\title{
Oral administration of 17 beta-estradiol over 3 months without progestin co-administration does not improve coronary flow reserve in post-menopausal women: a randomized placebo-controlled cross-over CMR study
}

Schwitter, Juerg ; Kozerke, Sebastian ; Bremerich, Jens ; Baltes, Christof ; Attenhofer Jost, Christine ; Birkhäuser, Martin ; Boesiger, Peter ; Buser, Peter

\begin{abstract}
BACKGROUND: Several large epidemiological outcome studies did not demonstrate a benefit of combined estrogen-progestin replacement treatment (HRT) on cardiovascular events in elderly postmenopausal women. Whether progestin antagonism is responsible for these negative results or the natural estrogen 17ss-estradial (E2) itself is not effective in the coronary circulation is unknown. AIM: To assess the effect of 3 months of E2 treatment on the coronary circulation, i.e., on coronary flow reserve (CFR), in postmenopausal women without established coronary artery disease (CAD). METHODS: In a double-blind placebo-controlled cross-over design postmenopausal women $(60+/-5$ years, $\mathrm{n}=14)$ were randomized to either start with placebo or E2 (Estrofem, Novo Nordisk, Copenhagen, Denmark) 2 mg/d given orally over 3 months and to switch thereafter for another 3 months of therapy. At baseline, a stress echocardiography was performed to exclude CAD. CFR was determined by coronary sinus CMR flow measurements (with motion-adapted gating and interactive acquisition window control; spatial/temporal resolution of $0.8 \times 0.9 \mathrm{~mm} 2 / 25-30 \mathrm{~ms}$ ) which were performed at rest and during vasodilation (dipyridamole $0.56 \mathrm{mg} / \mathrm{kg}$ over 4 minutes IV) at baseline, and after 3 and 6 months of therapy, respectively. RESULTS: Hemodynamics such as heart rate and systolic and diastolic blood pressure were not different for the control and E2 group. For CFR and for resting and hyperemic coronary sinus blood flow, no differences between the placebo and E2 group were found (2-way ANOVA for repeated measurements). Reproducibility of phase-contrast CMR measurements of CFR was $-1.1+/-4.9 \%$. CONCLUSIONS: In elderly postmenopausal women without significant CAD, oral administration of E2 over 3 months without a progestin co-administration does not improve CFR. This finding yields partly explanation for some large epidemiological trials which could not demonstrate a clinical cardiovascular benefit of HRT in elderly women.
\end{abstract}

DOI: https://doi.org/10.1080/10976640601138730

Posted at the Zurich Open Repository and Archive, University of Zurich

ZORA URL: https://doi.org/10.5167/uzh-95560

Journal Article

Published Version

Originally published at:

Schwitter, Juerg; Kozerke, Sebastian; Bremerich, Jens; Baltes, Christof; Attenhofer Jost, Christine; Birkhäuser, Martin; Boesiger, Peter; Buser, Peter (2007). Oral administration of 17beta-estradiol over 3 months without progestin co-administration does not improve coronary flow reserve in post-menopausal 
women: a randomized placebo-controlled cross-over CMR study. Journal of Cardiovascular Magnetic Resonance, 9(4):665-672.

DOI: https://doi.org/10.1080/10976640601138730 


\title{
Oral Administration of $17 \beta$-Estradiol Over 3 Months Without Progestin Co-Administration Does Not Improve Coronary Flow Reserve in Post-Menopausal Women: A Randomized Placebo-Controlled Cross-Over CMR Study
}

\author{
Juerg Schwitter, ${ }^{1}$ Sebastian Kozerke, ${ }^{2}$ Jens Bremerich, ${ }^{3}$ Christof Baltes, ${ }^{2}$ Christine Attenhofer Jost, ${ }^{1}$ \\ Martin Birkhäuser, ${ }^{5}$ Peter Boesiger, ${ }^{2}$ and Peter Buser ${ }^{4}$ \\ Clinic of Cardiology, University Hospital Zurich, Switzerland \\ Institute for Biomedical Engineering, University and ETH Zurich, Switzerland ${ }^{2}$ \\ Division of Radiology, University Hospital Basel, Switzerland ${ }^{3}$ \\ Cardiology, University Hospital Basel, Switzerland ${ }^{4}$ \\ Department of Internal Medicine, University Hospital Berne, Switzerland ${ }^{5}$
}

\begin{abstract}
Background: Several large epidemiological outcome studies did not demonstrate a benefit of combined estrogen-progestin replacement treatment (HRT) on cardiovascular events in elderly postmenopausal women. Whether progestin antagonism is responsible for these negative results or the natural estrogen $17 B$-estradial $\left(E_{2}\right)$ itself is not effective in the coronary circulation is unknown. Aim: To assess the effect of 3 months of $E_{2}$ treatment on the coronary circulation, i.e., on coronary flow reserve (CFR), in postmenopausal women without established coronary artery disease (CAD). Methods: In a double-blind placebo-controlled cross-over design postmenopausal women (60 \pm 5 years, $n=14)$ were randomized to either start with placebo or $E_{2}$ (Estrofem, Novo Nordisk, Copenhagen, Denmark) $2 \mathrm{mg} / \mathrm{d}$ given orally over 3 months and to switch thereafter for another 3 months of therapy. At baseline, a stress echocardiography was performed to exclude CAD. CFR was determined by coronary sinus CMR flow measurements (with motion-adapted gating and interactive acquisition window control; spatial/temporal resolution of $0.8 \times 0.9 \mathrm{~mm}^{2} / 25-30 \mathrm{~ms}$ ) which were performed at rest and during vasodilation (dipyridamole $0.56 \mathrm{mg} / \mathrm{kg}$ over 4 minutes IV) at baseline, and after 3 and 6 months of therapy, respectively. Results: Hemodynamics such as heart rate and systolic and diastolic blood pressure were not different for the control and $E_{2}$ group. For CFR and for resting and hyperemic coronary sinus blood flow, no differences between the placebo and $E_{2}$ group were found (2-way ANOVA for repeated measurements). Reproducibility of phase-contrast CMR measurements of CFR was $-1.1 \pm 4.9 \%$. Conclusions: In elderly postmenopausal women without significant CAD, oral administration of $E_{2}$ over 3 months without a progestin co-administration does not improve CFR. This finding yields partly explanation for some large epidemiological trials which could not demonstrate a clinical cardiovascular benefit of HRT in elderly women.
\end{abstract}

Received 8 November 2006; accepted 22 November 2006.

Keywords: Coronary Flow Reserve, Estrogen Replacement Therapy, Postmenopausal Women, Flow Measurements, Cardiovascular Magnetic Resonance.

This work was supported in part by the "Swiss National Science Foundation," the "Swiss Heart Foundation," and the "Strategic Excellence Project (SEP)" of the Federal Institute of Technology Zurich, Switzerland. Novo Nordisk, Denmark, is also acknowledged for providing verum and placebo medication for this study.

Correspondence to: J. Schwitter, MD

Cardiology, University Hospital Zurich

Raemistrasse 100, CH-8091 Zurich

Switzerland

tel: (+41) 44/255 3871; fax: (+41) 44/255 4401

email: juerg.schwitter@usz.ch 


\section{INTRODUCTION}

Several observational studies demonstrated that both estrogen replacement therapy (ERT) and hormone replacement therapy (HRT) (consisting of estrogen plus progestin) reduce the risk of coronary artery disease (CAD) (1-4). A variety of beneficial effects of estrogen on serum lipid levels (5-7), on inflammation $(8,9)$, arterial compliance and stiffness (10), and vasomotion of the brachial artery (11-14) have been reported. Less data are available for the coronary circulation. The natural 17ß-estradiol $\left(E_{2}\right)$ was shown to induce relaxation of precontracted coronary artery rings and to inhibit calcium influx in isolated cardiac myocytes (15). In a study of postmenopausal women, ethinyl estradiol also acutely attenuated abnormal vasomotor responses of coronary arteries to acetylcholine $(16,17)$. Despite this experimental and clinical evidence for favorable effects of estrogens on vascular pathophysiology, recent randomized controlled trials showed no benefit in postmenopausal women with CAD (18) or even an increased risk of cardiovascular events in elderly (mean age 63-66 years) women both with established CAD (19) or when predominantly healthy (20), which, however, was not the case in younger women $(4,21)$ and not in younger women using conjugated equine estrogen (CEE) alone $(22,23)$.

Several mechanisms may explain this discrepancy between these in part negative epidemiological outcome trials in elderly women on one hand and the positive smaller clinical studies, done mostly in younger women, on the other hand. Firstly, coadministration of a progestin to prevent uterine hyperplasia and malignancy could abolish the positive effects of estrogens. Combination of medroxy-progesterone acetate (MPA) with either CEE (24) or $\mathrm{E}_{2}$ (25) resulted in a reduced flow-mediated vasodilation (FMD) of the brachial artery measured by ultrasound compared to unopposed estrogen treatment. Also, cyclical $\mathrm{E}_{2}$ combined with norethisterone did not improve FMD (26). Secondly, some procoagulatory effects of estrogens could offset beneficial effects on vascular physiology (27). And the last point, initiation of HRT or ERT in more advanced stages of atherosclerotic disease (28) could prevent hormones from adequate action, since such action may depend on the integrity of the endothelium and estrogen receptors (29), according to the concept that estrogens would primarily prevent development of CAD rather than revert established disease. Besides, CEE or $\mathrm{E}_{2}$ itself may have limited beneficial long-term effects since many positive experimental and smaller clinical studies assessed acute effects of estrogens $(16,17)$ rather than long-term outcome. Considering these aspects, the following design was chosen for the current study. Postmenopausal women were randomized blindly to the natural estrogen $E_{2}$ or placebo, and no coadministration of progestin was allowed. The treatment period was set to 3 months in order to avoid testing of acute effects, and the study participants must not have obstructive CAD. The aim of this study was to test the hypothesis that $\mathrm{E}_{2}$ administered orally over 3 months without coadministration of progestins would improve coronary physiology, i.e., coronary flow reserve (CFR) in postmenopausal women with cardiovascular risk factors (RFs) but without established CAD. Due to the restrictive inclusion criteria which would affect the sample size, a cross-over design was applied. Furthermore, to assess the coronary circulation in a longitudinal study, noninvasive phase-contrast cardiovascular magnetic resonance (PC-CMR) flow measurements were performed. The large dimension of the coronary sinus (CS) and the fact that it drains a substantial portion of the left ventricular myocardium are ideal conditions to measure resting and hyperemic flow in this vessel by PC-CMR, and hence, to assess CFR (30-32).

\section{MATERIALS AND METHODS}

\section{Study population and design}

Fourteen postmenopausal women (mean age $60 \pm 5$ years, range: 53-67 years) were recruited for this study. They were eligible if they were between 50-70 years of age, had passed natural or surgical menopause for at least 1 year, or had follicle stimulating hormone (FSH) levels $>40 \mathrm{IU} / \mathrm{L}$ in case they were hysterectomized. Women with clinically overt CAD and/or with significant stenoses on $\mathrm{x}$-ray coronary angiography and/or a positive stress echocardiography examination (within 6 weeks before study participation) were not eligible as were women with cardiomyopathies or predominant valvular heart disease. Also, calcium antagonist treatment was not allowed (since $\mathrm{E}_{2}$ may exert calcium antagonistic effects). Further exclusion criteria were HRT or ERT prior to study participation, a history and/or evidence of uterine or breast cancer on gynecological examination (performed within 12 months before study participation), a history of deep vein thrombosis or thromboembolism, and contraindications for CMR examination or dipyridamole administration.

The study protocol was approved by the local Ethics Committees, and all study participants gave written informed consent.

In a double-blind, placebo-controlled, cross-over design the study participants were randomized to either start with placebo or $\mathrm{E}_{2}$ (Estrofem, Novo Nordisk) $2 \mathrm{mg} / \mathrm{d}$ given orally over 3 months and to switch thereafter for another 3 months of therapy (Fig. 1). Randomization was performed by the Institute of Biostatistics, University of Zurich, Switzerland (B. Seifert, PhD). CMR studies were performed at baseline (MR1), and after 3 and 6 months of therapy (MR2 and MR3), respectively.

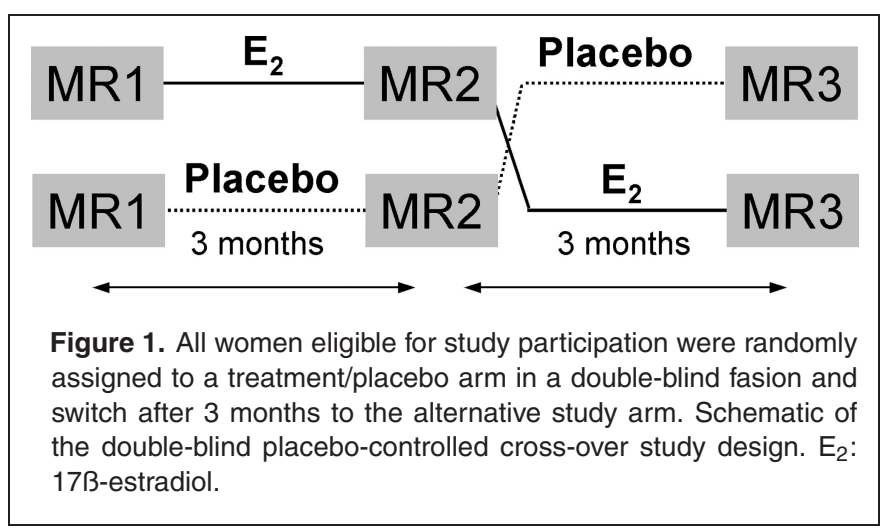




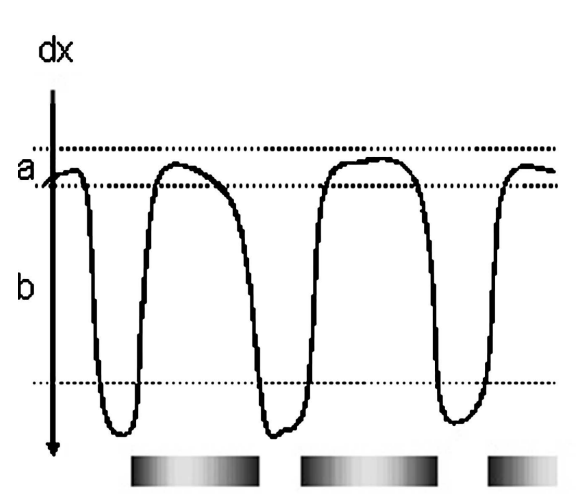

a

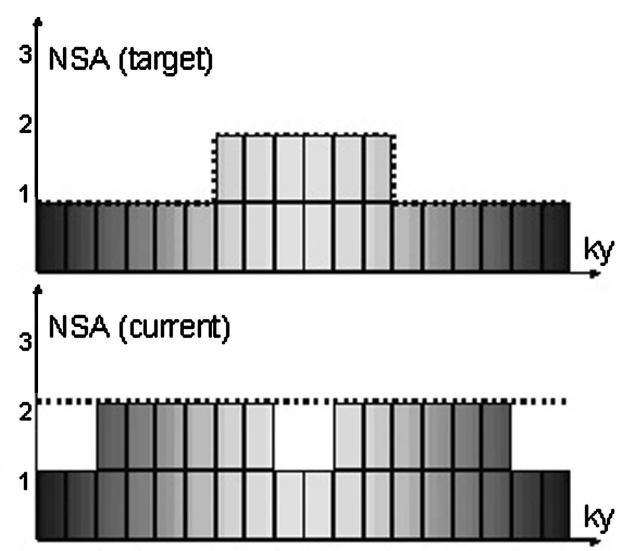

b

Figure 2. a) Motion Adapted Gating (MAG) controls phase-encoding according to the actual displacement (dx) of the diaphragm. Displacements within the $5 \mathrm{~mm}$ window (a) led to proposals for profile $\mathrm{k}_{\mathrm{y}}=0$. Within a $12 \mathrm{~mm}$ window (b) MAG was performed. b) A target function defines the minimum number of signal averages (NSA [target]) required per profile $\mathrm{k}_{\mathrm{y}}$. In case of short-term drifts profiles other than the required can be averaged until the target function is fulfilled (NSA [current]).

\section{MR imaging}

Each subject was imaged in supine position on a $1.5 \mathrm{~T}$ system (Philips Medical Systems, Best, The Netherlands) using a 5 element cardiac phased-array coil. After measurement of left ventricular volumes and function by short-axis cine images, localizers were acquired depicting the CS in-plane. The site of flow measurements was then defined by an imaging plane transecting the center of both, the left atrium and the aortic root, thereby cutting the CS perpendicularly (31). To allow for velocity mapping with sufficient spatial and temporal resolutions, free-breathing acquisitions employing a modified navigatorbased motion-adapted gating (33) and tracking (34) approach was implemented. A cubic weighting function was used to control phase-encoding according to the actual displacement of the diaphragm (Fig. 2a). Small displacements of less than $5 \mathrm{~mm}$ led to the acquisition of central $\mathrm{k}$-space profiles according to the target function explained below, whereas larger displacements triggered encoding of higher spatial frequencies. Only diaphragm displacements within a $17 \mathrm{~mm}$ constant gating window were marked valid. Displacements beyond the $17 \mathrm{~mm}$ window led to rejection of the acquired data. Accepted data could potentially be averaged in the central $45 \%$ of $\mathrm{k}$-space according to the target function shown in Figure $2 b$, thereby improving the signal-to-noise ratio in the final images while efficiently using data in case of high gating efficiencies for the given scan time of approximately $4 \mathrm{~min}$. For all respiratory positions inside the gating window of $17 \mathrm{~mm}$, tracking was performed with a correction factor of 0.8 , i.e., a displacement of the diaphragm of $10 \mathrm{~mm}$ was scaled to $8 \mathrm{~mm}$ at the level of the coronary sinus cross-section (35). Since breathing patterns can exhibit temporary changes and sudden drifts in particular during stress exams in some subjects, the operator was allowed to adapt the gating window level interactively during the scan, thereby preventing varying gating efficiencies.
Scan parameters for phase-contrast velocity mapping were as follows: measured spatial resolution: $0.8 \times 0.9 \mathrm{~mm}^{2}$, slice thickness: $5 \mathrm{~mm}$, temporal resolution: $25-30 \mathrm{~ms}$ depending on heart rate, velocity encoding (venc): $60 \mathrm{~cm} / \mathrm{s} / \pi, \mathrm{T}_{\mathrm{E}}: 7.8 \mathrm{~ms}$. The two velocity encoding segments were balanced and measured consecutively in the same heart phase. Scan durations were 4:28 min and 4:05 min on average assuming heart rates of 65 beats/min and 80 beats/min and gating efficiencies of $85 \%$ and $77 \%$ during the resting and stress states, respectively.

\section{Statistics}

Values are given as mean $\pm \mathrm{SD}$. The assessment of treatment effects on CFR, resting, and hyperemic CS flow as well as on blood pressure and heart rate involved a repeated measures ANOVA ( 2 within factors: treatment groups: $\mathrm{E}_{2}$ vs placebo and time points: baseline vs follow-up), followed by paired tests and Bonferroni's correction ( $p<0.05 / 4$ is significant because of 4 comparisons; StatView v5.0.1, SAS Institute Inc., USA). Baseline measurements included all MR1 measurements and follow-up measurements included the MR2 and MR3 measurements for each treatment group (i.e., $M R 2$ and $M R 3$ for $E_{2}$ group vs MR2 and MR3 for the placebo group).

Reproducibility for CFR, resting, and hyperemic CS flow measurements was calculated from baseline and follow-up studies under the placebo regimen (all MR1 studies vs MR2 and MR3 studies of the placebo group). Reproducibility is given as the mean $\pm \mathrm{SD}$ of paired measurements $\left(=\mathrm{SD}_{\text {Diff }}\right)$ and corresponding $95 \%$ confidence intervals (36).

For an assumed difference in CFR between $\mathrm{E}_{2}$ and placebo of approximately $10 \%$ (37) with an interstudy reproducibility of $4.9 \%\left(=\mathrm{SD}_{\text {Diff }}\right)$ by PC-MR, the study yields a power of $90 \%$ to detect differences at a $p$ value of 0.01 in a sample size of 15 subjects (38). 


\begin{tabular}{|c|c|}
\hline$n$ & 14 \\
\hline Age (years) & $58 \pm 5$ \\
\hline Height (cm) & $161 \pm 6$ \\
\hline Weight $(\mathrm{kg})$ & $67 \pm 9$ \\
\hline Body mass index $\left(\mathrm{kg} / \mathrm{m}^{2}\right)$ & $26 \pm 3.7$ \\
\hline Estradiol (menopause $<100 \mathrm{pmol} / \mathrm{L}$ ) & $48 \pm 13$ \\
\hline Risk factors: & $2.0 \pm 0.9$ \\
\hline Arterial hypertension & $8(57)$ \\
\hline Hypercholesterolemia & $4(29)$ \\
\hline Diabetes mellitus & $2(14)$ \\
\hline Smoking & $1(7)$ \\
\hline Positive family history & $1(7)$ \\
\hline \multicolumn{2}{|l|}{ Medication: } \\
\hline Beta-blockers & 6 \\
\hline ACEI & 4 \\
\hline Statins & 4 \\
\hline Insulin & 2 \\
\hline History of hysterectomy & 5 \\
\hline Stress-Echocardiography & 11 \\
\hline X-ray coronary angiography & 3 \\
\hline
\end{tabular}

\section{RESULTS}

Demographics of the study population are given in Table 1. Two patients had to be excluded from the study due to headache over several days $(\mathrm{n}=1)$ and vomiting after vasodilation at MR1 $(\mathrm{n}=1)$ resulting in 12 patients included in the analysis. In the 12 women, 1 CMR study (MR 3) was not evaluable due to caffeine intake at the day of the CMR study, in 2 patients 1 CMR study was technically inadequate. An example of CMR images for MR1, MR2, and MR3 is given in Figure 3, together with corresponding resting and hyperemic CS flow curves in Figure 4. Medication included antihypertensive treatment (in 8 patients), statins (in 4), and antidiabetic treatment (in 2), which were all continued during the entire study. Hemodynamics such as heart rate, systolic, and diastolic blood pressures were not different for the control and $\mathrm{E}_{2}$ group as shown in Figures 5 and 6, respectively. No differences between the placebo and $\mathrm{E}_{2}$ group were found for hyperemic CS blood flow $(p=0.60 ; p$ value for the interaction between treatment groups and timepoints, repeated measures ANOVA), neither for resting CS blood flow $(\mathrm{p}=0.51$; Fig. 7$)$, nor for CFR $(\mathrm{p}=0.16$; Fig. 8).

Reproducibility for CFR measurements with PC-MR expressed as mean difference $\pm \mathrm{SD}$ of paired measurements determined in the placebo group with a mean CFR of $2.55 \pm 0.33$ was $-0.021 \pm 0.13(-1.1 \pm 4.9 \%)$.

\section{DISCUSSION}

The current study results indicate that a 3 month treatment period of postmenopausal women with $\mathrm{E}_{2}$ does improve neither maximum myocardial perfusion nor CFR. In the current study population of postmenopausal women without established CAD, CFR ranged from 2.35 to 2.96. In a study using PET imaging similar CFR, values of 2.05 to 2.51 were obtained in postmenopausal women with RFs (37). In this study by Campisi et al , CFR and dipyridamole-induced hyperemic myocardial blood flow were $22 \%$ and $11 \%$ higher during HRT than without therapy, respectively, although these differences did not reach statistical significance. However, in their study both, ERT and HRT were mixed in the active treatment group, which could explain a lack of CFR improvement due to progestin antagonism. In the current study with unopposed $\mathrm{E}_{2}$ treatment, no difference was found between the $E_{2}$ and the placebo group for both CFR and dipyridamole-induced hyperemic myocardial blood flow. These data indicate that CFR and hyperemic myocardial blood flow do not increase with either $\mathrm{E}_{2}$ alone or with combined estrogen/progestin treatment. Assuming that CFR and maximum myocardial blood flow are reflecting coronary vascular health status, the current findings are in line with large clinical prospective trials which demonstrated in elderly postmenopausal and predominantly healthy women no beneficial effect of HRT (20) and ERT (23) on cardiovascular event rates.

When comparing the current study results on coronary circulation obtained in women without CAD with those of other vascular territories such as the brachial or carotid arteries in

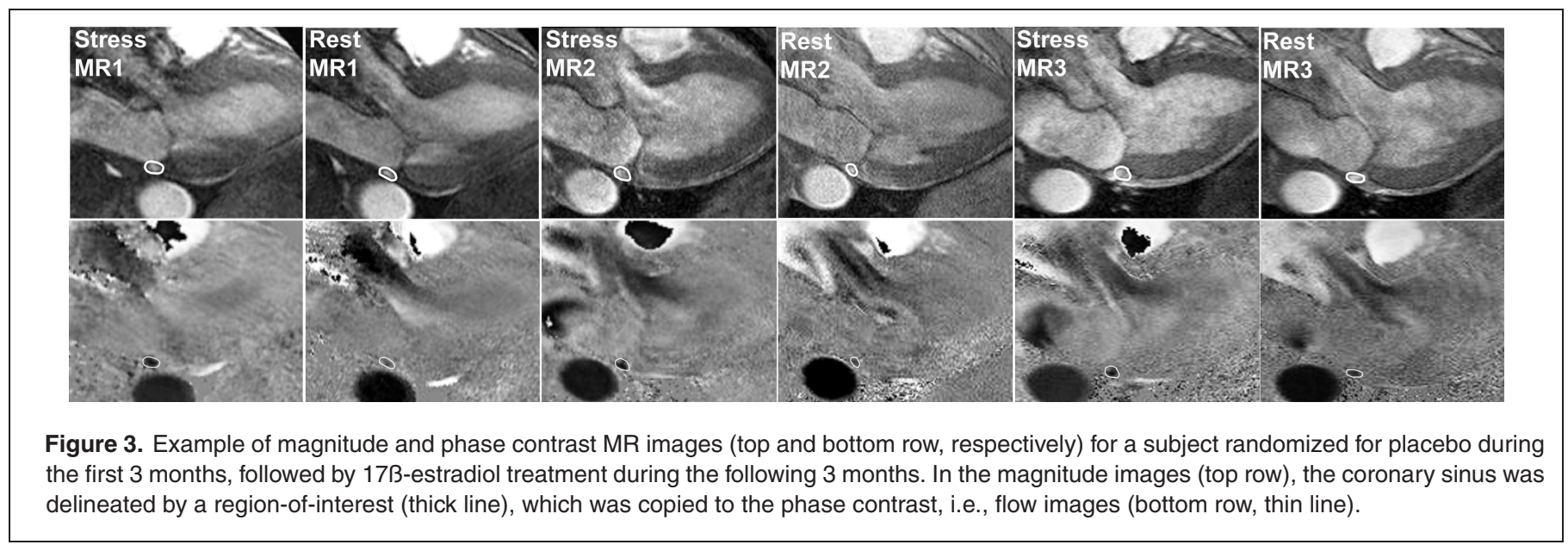



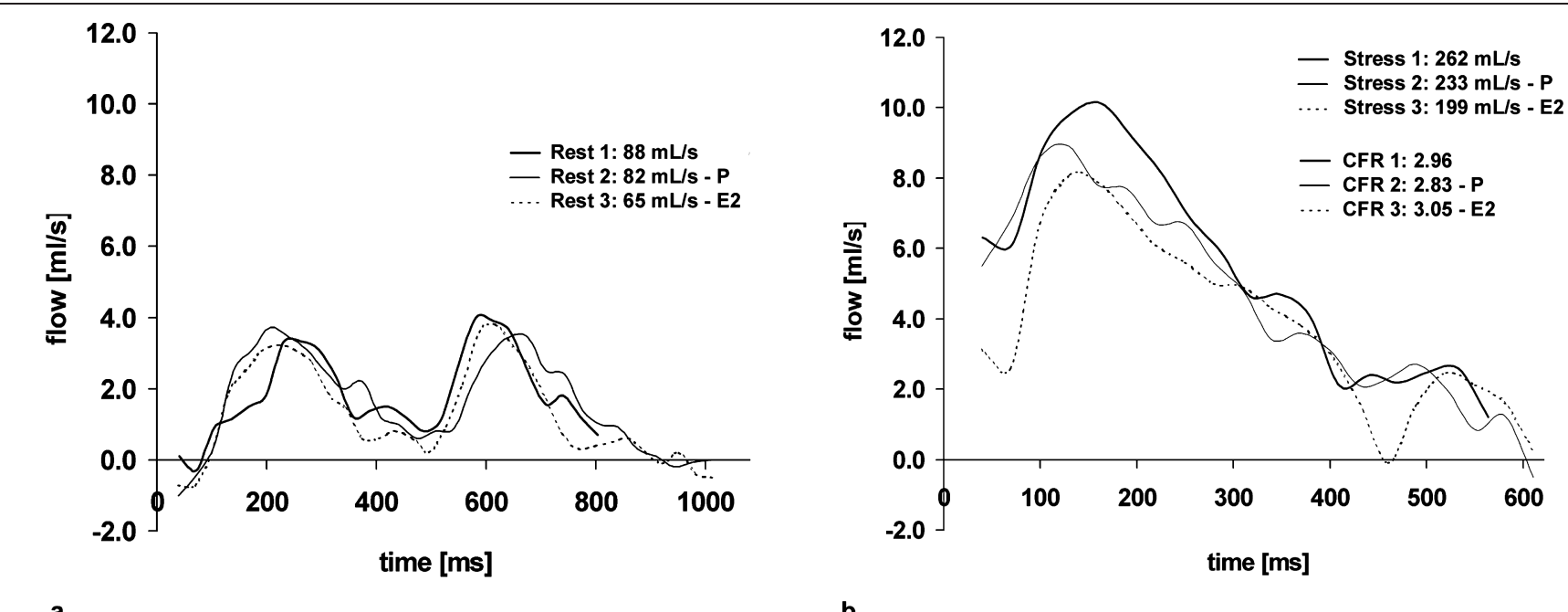

a

Figure 4. Example of resting and stress coronary sinus flow curves derived from the image set shown in Figure 3. $P=$ placebo, $E 2=17 ß-e s t r a d i o l$, Rest 1-3, Stress 1-3, and CFR 1-3 indicate baseline, first follow-up, and second follow-up CMR study, respectively.

postmenopausal women without CAD, similar findings were reported. In a large prospective study testing FMD of the brachial artery as a marker of vascular health, 253 postmenopausal women were randomized to either HRT or no therapy and were followed for a mean of 2.9 years (26). After elimination of 153 patients from analysis due to drop outs, in the 100 remaining patients, no difference in FMD was found between HRT and the placebo group. Similarly, in another large study 321 postmenopausal women were recruited for measurements of carotid artery distensibility and were randomized to low and high dose HRT or no therapy. Drop out was $46 \%$ and in the remaining population, no effect of HRT on distensibility was found (39). Finally, in a randomized, double-blind, placebo-controlled trial unopposed $\mathrm{E}_{2}$ reduced progression of intima-media-thickness measured by sonography in the carotid arteries in postmenopausal women compared with placebo but did not influence progression in those women with controlled lipid levels (40).

In postmenopausal women with established CAD neither HRT nor ERT had a beneficial effect on the coronary macrocirculation, i.e., progression of coronary artery stenoses was not altered (41). However, there were positive effects of $E_{2}$ on coronary circulatory function in postmenopausal women with established CAD by attenuating acetylcholine-induced coronary artery constriction (17). Similarly, in the forearm microcirculation of postmenopausal women blood flow at baseline (i.e., prior to $E_{2}$ treatment) of $10.2 \mathrm{~mL} / \mathrm{min} / 100 \mathrm{~g}$ (during acetylcholine infusion) increased to $17.9 \mathrm{~mL} / \mathrm{min} / 100 \mathrm{~g}$ after 12 weeks of $E_{2}$ treatment (42). In this study, also sodium nitroprussideaugmented microcirculatory flow of $10.3 \mathrm{~mL} / \mathrm{min} / 100 \mathrm{~g}$ further increased to $17.9 \mathrm{~mL} / \mathrm{min}$ after 12 weeks of $\mathrm{E}_{2}$ treatment. In an CMR study in healthy premenopausal women, the forearm macrocirculation also exhibited increased FMD during midcycle compared with the menstrual phase with high and low levels of $E_{2}$, respectively (43).
These findings illustrate that $\mathrm{E}_{2}$ mechanisms of action may differ in different vascular beds, such as in coronary microcirculation (37 and present study), coronary macrocirculation $(17,41)$, brachial macrocirculation $(26,43)$, forearm microcirculation (42), and carotid artery macrocirculation (40). Also the status of the endothelium, i.e., preclinical disease (37, 40 and the present study) vs established atherosclerotic disease $(17,41)$ may influence the effects of $E_{2}$ treatment on the vascular parameters measured. This could be one reason among many others for the different effects of $E_{2}$ in different vascular territories since atherosclerosis is known to progress differently in various vascular regions. It is noteworthy that large randomized clinical trials were negative when performed in women with proven CAD with respect to clinical outcome (18) as well as morphologic

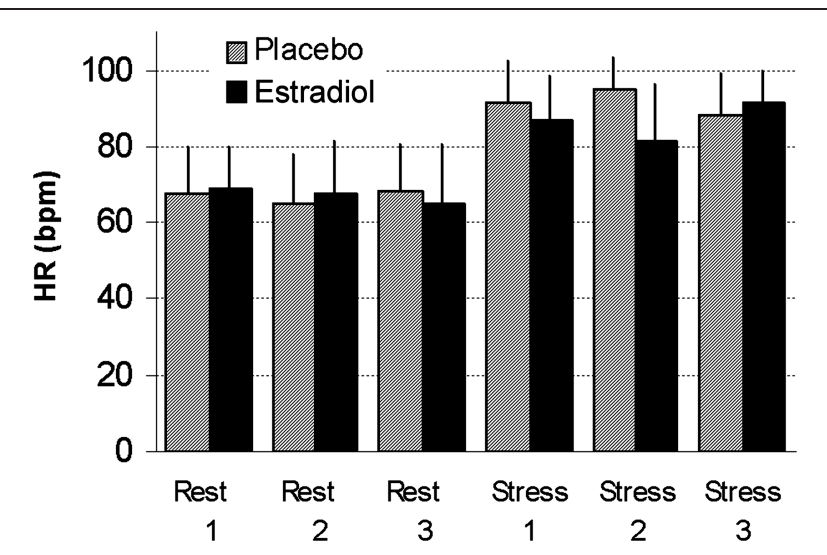

Figure 5. Bar graph demonstrating heart rates (HR in beat per minute) during resting and stress condition for the placebo and 17ß-estradiol group. No significant differences occurred. Bpm = beats per minute. 


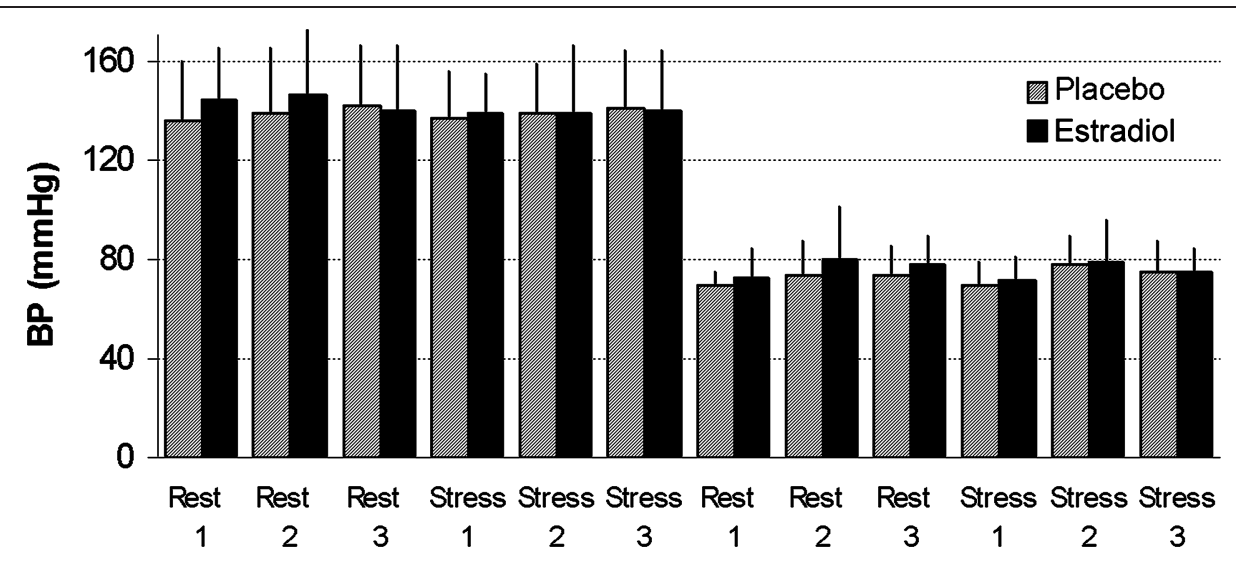

Figure 6. Bar graph demonstrating systolic and diastolic blood pressure (BP) during resting and stress condition for the placebo and 17ß-estradiol group. No significant differences occurred.

progression of CAD $(19,41)$. In the present study, participants had preclinical CAD only and, thus, a lack of an $E_{2}$ effect on CFR does not directly explain the negative clinical outcome of the large clinical trials mentioned above. While estrogen receptors are diminished in atherosclerotic lesions in women (29), the estrogens themselves may show different affinities or different conformations of the ligand-receptor complex yielding different effects in different tissues. The field of selective estrogen receptor modulators (SERM) opens the opportunity to design specific compounds which exert beneficial effects in the cardiovascular system, while being inactive in other tissues, such as breast or endometrium. Raloxifene, a SERM approved for osteoporosis prevention and treatment, was shown to restore endothelial nitric oxide release in ovariectomized female rats (44) and in a subpopulation of women at increased cardiovascular risk in the MORE trial (Multiple Outcomes of Raloxifene Evaluation), fewer cardiovascular events occurred with raloxifene versus placebo (45). In extended follow up, this advantage was no longer present, which was discussed in light of selection bias,

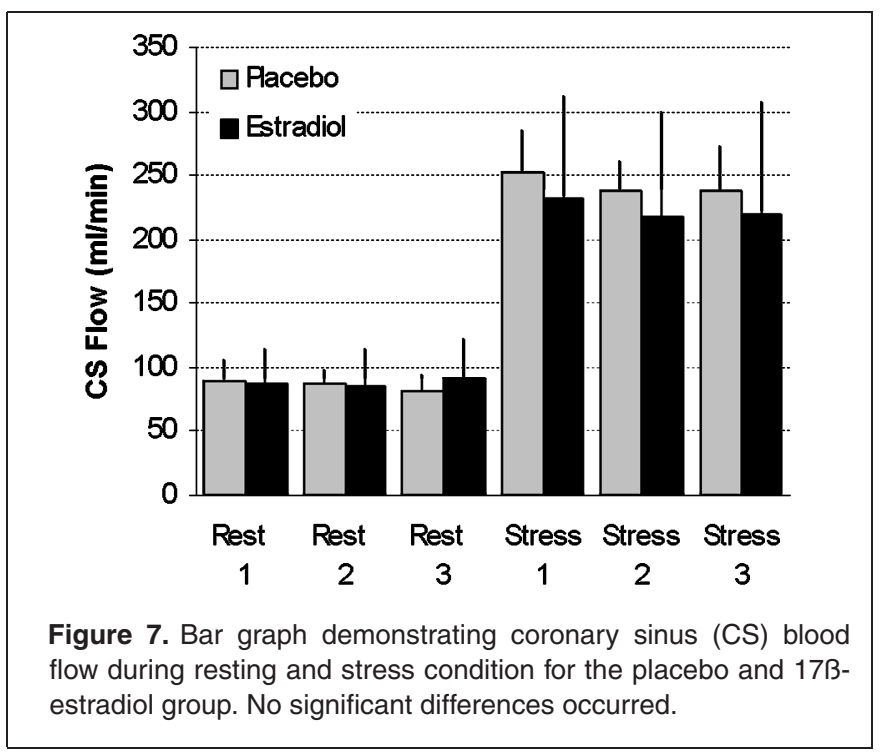

but could also be a consequence of changes in receptor density with progressive disease (46).

In addition to these pathophysiological considerations based on prospective, randomized, double-blind, and placebocontrolled trials $(23,40)$, some other positive studies $(11,13$, $24,47-51)$ had some major limitations in study design. Several of these positive studies had no placebo control group (13, $24,48-50$ ), were observational in nature (51), or were small in sample size (24), which makes correction for underlying RFs profiles problematic (unless a cross-over design is applied). In the present study, limitations with regard to study design were minimized, and as a result, it could be demonstrated that unopposed $E_{2}$ administered orally over 3 months had no beneficial effect on the myocardial microcirculation in postmenopausal women without CAD.

\section{Limitations of the study}

Although the study was performed in a placebo-controlled, randomized, double-blind fashion, there still remain some

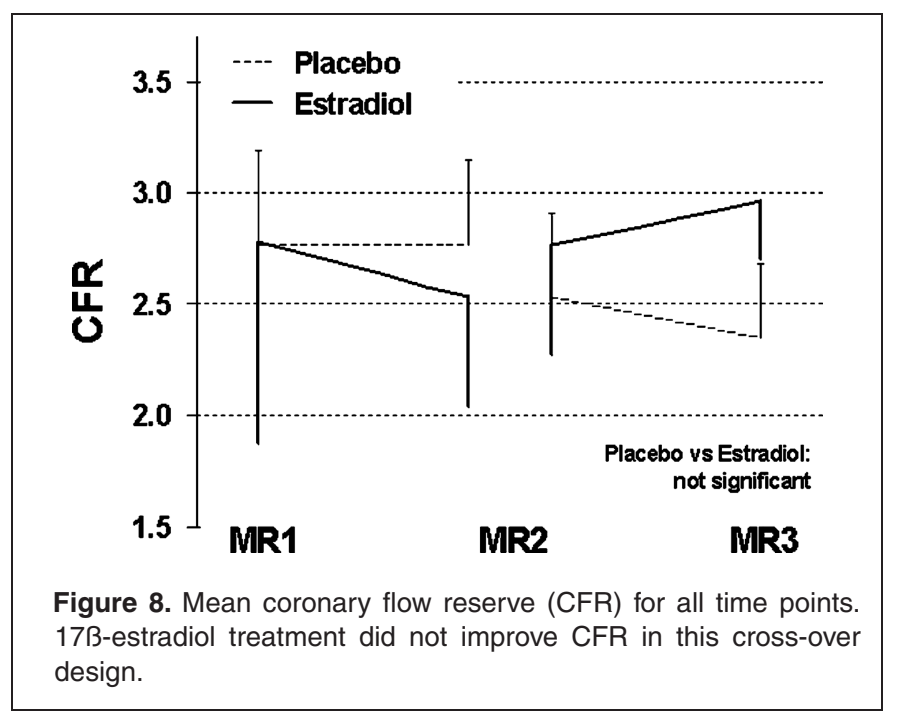


limitations. Particularly, the treatment period of 3 months might have been too short for $\mathrm{E}_{2}$ treatment to fully develop the beneficial changes in vascular physiology and/or morphology. However, if the treatment periods would have been considerably longer, this could have led to a selection bias toward women with high acceptance of hormone treatment (subjecting the study to a limitation similar to observational studies) and maybe a higher risk of side effects of $\mathrm{E}_{2}$. A second limitation is the age of the patients; as it has been suggested by a large prospective, randomized, double-blind and placebo-controlled clinical trial $(21,23,52)$, women with a distance less than 10 years from menopause may behave differently than women with a more distant menopause ("window of opportunity").

Dipyridamole increases myocardial blood flow by acting on smooth muscle cells. Increased flow then induces endotheliummediated vasodilation by increased endothelial shear stress. Thus, dipyridamole indirectly stimulates endothelial-dependent flow increase, and accordingly, an impairment of dipyridamoleinduced hyperemic flow has been shown in the presence of RFs (37). Therefore, it appears justified to use this pharmacological agent to test whether $\mathrm{E}_{2}$ could revert or mitigate some adverse effects of RFs on endothelial function.

Finally, neither serum lipids nor inflammatory markers were measured in this study to focus on the single question: whether $\mathrm{E}_{2}$ can improve coronary vascular function without addressing potential mechanisms of $\mathrm{E}_{2}$ action. The treatment regimens between women were somewhat heterogeneous. The cross-over design, however, should mostly correct for this limitation (no treatment was changed during the placebo and treatment phase in any patient besides the study drug).

Despite the relatively small sample size in this study, the nonsignificant $\mathrm{p}$ value $(>0.05)$ for differences in CFR indicates that $\mathrm{E}_{2}$ treatment affects the CFR by less than $\pm 8 \%$ (at a power of $80 \%$ ), i.e., the effect of $E_{2}$, if at all present, is unlikely to be of clinical relevance.

\section{CONCLUSIONS}

In elderly postmenopausal women without significant CAD, oral administration of $E_{2}$ over 3 months without a progestin coadministration does not improve CFR. This finding yields partly explanation for some large epidemiological trials which could not demonstrate a clinical cardiovascular benefit of HRT in elderly women.

\section{REFERENCES}

1. Grodstein F, Stampfer MJ, Manson JE, Colditz GA, Willett WC, Rosner B, et al. Postmenopausal estrogen and progestin use and the risk of cardiovascular disease. N Engl J Med 1996;335:453-61. [erratum appears in N Engl J Med 1996;335:1406.

2. Psaty BM, Heckbert SR, Atkins D, Lemaitre R, Koepsell TD, Wahl $\mathrm{PW}$, et al. The risk of myocardial infarction associated with the combined use of estrogens and progestins in postmenopausal women. Arch Int Med 1994;154:1333-9.

3. Varas-Lorenzo C, Garcia-Rodriguez LA, Perez-Gutthann S, Duque-Oliart A. Hormone replacement therapy and incidence of acute myocardial infarction. A population-based nested casecontrol study. Circulation 2000;101:2572-8.

4. Grodstein F, Manson JE, Stampfer MJ. Hormone therapy and coronary heart disease: the role of time since menopause and age at hormone initiation. J Women's Health 2006;15:3544.

5. Effects of estrogen or estrogen/progestin regimens on heart disease risk factors in postmenopausal women. The Postmenopausal Estrogen/Progestin Interventions (PEPI) Trial. The Writing Group for the PEPI Trial. JAMA 1995;273:199-208. [erratum appears in JAMA 1995; 6; 274:1676.

6. Soma MR, Osnago-Gadda I, Paoletti R, Fumagalli R, Morrisett JD, Meschia M, et al. The lowering of lipoprotein[a] induced by estrogen plus progesterone replacement therapy in postmenopausal women. Arch Int Med 1462;153:1462-8.

7. Subbiah MT, Kessel B, Agrawal M, Rajan R, Abplanalp W, Rymaszewski Z. Antioxidant potential of specific estrogens on lipid peroxidation. J Clin Endocrin \& Metab 1993;77:1095-7.

8. Koh KK, Bui MN, Mincemoyer R,Cannon III RO. Effects of hormone therapy on inflammatory cell adhesion molecules in postmenopausal healthy women. Am J Cardiol 1997;80:1505-7.

9. Wakatsuki A, Okatani $Y$, Ikenoue N, Fukaya T. Effect of medroxyprogesterone acetate on vascular inflammatory markers in postmenopausal women receiving estrogen. Circulation 2002;105:1436-9.

10. Rajkumar C, Kingwell BA, Cameron JD, Waddell T, Mehra R, Christophidis N, et al. Hormonal therapy increases arterial compliance in postmenopausal women. J Am Coll Cardiol 1997;30:3506.

11. Koh KK, Cardillo C, Bui MN, Hathaway L, Csako G, Waclawiw MA, et al. Vascular effects of estrogen and cholesterol-lowering therapies in hypercholesterolemic postmenopausal women. Circulation 1999;99:354-60.

12. Lieberman EH, Gerhard MD, Uehata A, Walsh BW, Selwyn AP, Ganz P, et al. Estrogen improves endothelium-dependent, flowmediated vasodilation in postmenopausal women. Ann Int Med 1994;121:936-41.

13. Koh KK, Blum A, Hathaway L, Mincemoyer R, Csako G, Waclawiw MA, Panza JA, at al. Vascular effects of estrogen and vitamin $E$ therapies in postmenopausal women. Circulation 1999;100:18517.

14. Gilligan DM, Badar DM, Panza JA, Quyyumi AA ,Cannon III RO. Acute vascular effects of estrogen in postmenopausal women. Circulation 1994;90:786-91.

15. Jiang C, Sarrel PM, Poole-Wilson PA, Collins P. Acute effect of 17 beta-estradiol on rabbit coronary artery contractile responses to endothelin-1. Am J Physiol 1992;263.

16. Reis SE, Gloth ST, Blumenthal RS, Resar JR, Zacur HA, Gerstenblith G, et al. Ethinyl estradiol acutely attenuates abnormal coronary vasomotor responses to acetylcholine in postmenopausal women. Circulation 1994;89:52-60.

17. Collins P, Rosano GM, Sarrel PM, Ulrich L, Adamopoulos S, Beale $\mathrm{CM}$, et al. 17 beta-Estradiol attenuates acetylcholine-induced coronary arterial constriction in women but not men with coronary heart disease. Circulation 1995;92:24-30.

18. Grady D, Herrington D, Bittner V, Blumenthal R, Davidson M, Hlatky $\mathrm{M}$, et al. Cardiovascular disease outcomes during 6.8 years of hormone therapy: Heart and Estrogen/progestin Replacement Study follow-up (HERS II). JAMA 2002; 288: 49-57. [erratum appears in JAMA 2002;4;288:1064].

19. Herrington DM, Reboussin DM, Brosnihan KB, Sharp PC, Shumaker SA, Snyder TE, et al. Effects of estrogen replacement on the progression of coronary-artery atherosclerosis. $\mathrm{N}$ Engl $\mathrm{J}$ Med 2000;343:522-9.

20. Rossouw JE, Anderson GL, Prentice RL, LaCroix AZ, Kooperberg $\mathrm{C}$, Stefanick ML, et al. Risks and benefits of estrogen plus progestin in healthy postmenopausal women: principal results From 
the Women's Health Initiative randomized controlled trial. JAMA 2002;288:321-33.

21. Manson JE, Hsia J, Johnson KC, Rossouw JE, Assaf AR, Lasser $\mathrm{NL}$, et al. Estrogen plus progestin and the risk of coronary heart disease.[see comment]. N Engl J Med 2003;349:523-34.

22. Hsia J, Langer RD, Manson JE, Kuller L, Johnson KC, Hendrix SL, et al. Conjugated Equine Estrogens and Coronary Heart Disease The Women's Health Initiative. Arch Int Med 2006;166:357-65.

23. Anderson GL, Limacher M, Assaf AR, Bassford T, Beresford SA, Black $\mathrm{H}$, et al. Effects of conjugated equine estrogen in postmenopausal women with hysterectomy: the Women's Health Initiative randomized controlled trial. JAMA 2004;291:1701-12.

24. Wakatsuki A, Okatani $\mathrm{Y}$, Ikenoue N, Fukaya T. Effect of medroxyprogesterone acetate on endothelium-dependent vasodilation in postmenopausal women receiving estrogen. Circulation 2001;104:1773-8.

25. Kawano H, Motoyama T, Hirai N, Yoshimura T, Kugiyama K, Ogawa $\mathrm{H}$, et al. Effect of medroxyprogesterone acetate plus estradiol on endothelium-dependent vasodilation in postmenopausal women. Am J Cardiol 2001;87:238-40.

26. Sorensen KE, Dorup I, Hermann AP ,Mosekilde L. Combined hormone replacement therapy does not protect women against the age-related decline in endothelium-dependent vasomotor function. Circulation 1998;97:1234-8.

27. Caine YG, Bauer KA, Barzegar S, ten Cate H, Sacks FM, Walsh $\mathrm{BW}$, et al. Coagulation activation following estrogen administration to postmenopausal women. Thromb \& Haemost 1992;68:392-5.

28. Mikkola TS, Clarkson TB. Estrogen replacement therapy, atherosclerosis, and vascular function. Cardiovasc Research 2002;53:605-19.

29. Losordo DW, Kearney M, Kim EA, Jekanowski J ,Isner JM. Variable expression of the estrogen receptor in normal and atherosclerotic coronary arteries of premenopausal women. Circulation 1994;89:1501-10.

30. van Rossum AC, Visser FC, Hofman MB, Galjee MA, Westerhof N, Valk J. Global left ventricular perfusion: noninvasive measurement with cine MR imaging and phase velocity mapping of coronary venous outflow. Radiology 1992;182:685-91.

31. Schwitter J, DeMarco T, Kneifel S, von Schulthess GK, Jorg MC, Arheden $\mathrm{H}$, et al. Magnetic resonance-based assessment of global coronary flow and flow reserve and its relation to left ventricular functional parameters: a comparison with positron emission tomography. Circulation 2000;101:2696-702.

32. Lund GK, Wendland MF, Shimakawa A, Arheden H, Stahlberg F, Higgins $\mathrm{CB}$, et al. Coronary sinus flow measurement by means of velocity-encoded cine MR imaging: validation by using flow probes in dogs. Radiology 2000;217:487-93.

33. Weiger $M$, Bornert $P$, Proska $R$, Schaffter $T$, Haase A. Motion-adapted gating based on k-space weighting for reduction of respiratory motion artifacts. Magn Reson Med 1997;38:322-33.

34. McConnell M, Khasgiwala V, Savord B, Chen M, Chuang M, Edelman R, et al. Prospective adaptive navigator correction for breath-hold MR coronary angiography. Magn Reson Med 1997;37:148-52.

35. Wang $\mathrm{Y}$, Riederer S, Ehman R. Respiratory motion of the heart: kinematics and the implications for the spatial resolution of coronary imaging. Magn Reson Med 1995;33:713-19.

36. Bland JM, Altman DG. Statistical methods for assessing agreement between two methods of clinical measurement. Lancet 1986;1:307-10.

37. Campisi R, Nathan L, Pampaloni MH, Schoder H, Sayre JW, Chaudhuri G, et al.. Noninvasive assessment of coronary microcirculatory function in postmenopausal women and effects of short-term and long-term estrogen administration.Circulation 2002;105:425-30.

38. Bland D. Practical statistics for medical research. London: Chapman and Hall: 1991;455-60.

39. Angerer P, Kothny W, Stork S, von Schacky C. Hormone replacement therapy and distensibility of carotid arteries in postmenopausal women: a randomized, controlled trial. J Am Coll Cardiol 1789;36:1789-96.

40. Hodis HN, Mack WJ, Lobo RA, Shoupe D, Sevanian A, Mahrer PR, et al. Estrogen in the prevention of atherosclerosis. A randomized, double-blind, placebo-controlled trial. Ann Int Med 2001;135:939_ 53

41. Hodis HN, Mack WJ, Azen SP, Lobo RA, Shoupe D, Mahrer $\mathrm{PR}$, et al. Hormone therapy and the progression of coronaryartery atherosclerosis in postmenopausal women. N Engl $\mathrm{J}$ Med 2003;349:535-45.

42. Vehkavaara $S$, Hakala-Ala-Pietila $T$, Virkamaki A, Bergholm R, Ehnholm C, Hovatta $O$, et al. Differential effects of oral and transdermal estrogen replacement therapy on endothelial function in postmenopausal women. Circulation 2000;102:268793.

43. Sorensen MB, Collins P, Ong PJL, Webb CM, Hayward CS, Asbury $\mathrm{EA}$, et al. Long-term use of contraceptive depot medroxyprogesterone acetate in young women impairs arterial endothelial function assessed by cardiovascular magnetic resonance. Circulation 2002;106:1646-51.

44. Wong CM, Yao X, Au CL, Tsang SY, Fung KP, Laher I, et al. Raloxifene prevents endothelial dysfunction in aging ovariectomized female rats. Vasc Pharmacol 2006;44:290-8.

45. Barrett-Connor E, Grady D, Sashegyi A, Anderson PW, Cox DA, Hoszowski K, et al. Raloxifene and cardiovascular events in osteoporotic postmenopausal women: four-year results from the MORE (Multiple Outcomes of Raloxifene Evaluation) randomized trial. JAMA 2002;287:847-57.

46. Ensrud K, Genazzani AR, Geiger MJ, McNabb M, Dowsett SA Cox DA, et al. Effect of raloxifene on cardiovascular adverse events in postmenopausal women with osteoporosis. Am J Cardiol 2006;97:520-7.

47. Gerhard M, Walsh BW, Tawakol A, Haley EA, Creager SJ, Seely $\mathrm{EW}$, et al. Estradiol therapy combined with progesterone and endothelium-dependent vasodilation in postmenopausal women. Circulation 1158;98:1158-63.

48. Koh KK, Jin DK, Yang SH, Lee SK, Hwang HY, Kang MH, et al. Vascular effects of synthetic or natural progestagen combined with conjugated equine estrogen in healthy postmenopausal women. Circulation 2001;103:1961-6.

49. Herrington DM, Werbel BL, Riley WA, Pusser BE, Morgan TM. Individual and combined effects of estrogen/progestin therapy and lovastatin on lipids and flow-mediated vasodilation in postmenopausal women with coronary artery disease. J Am Coll Cardiol 1999;33:2030-7.

50. Sanada M, Higashi Y, Nakagawa K, Sasaki S, Kodama I, Tsuda $\mathrm{M}$, et al. Relationship between the angiotensin-converting enzyme genotype and the forearm vasodilator response to estrogen replacement therapy in postmenopausal women. J Am Coll Cardiol 2001;37:1529-35.

51. McCrohon JA, Adams MR, McCredie RJ, Robinson J, Pike A, Abbey $\mathrm{M}$, et al. Hormone replacement therapy is associated with improved arterial physiology in healthy post-menopausal women. Clinical Endocrinology 1996;45:435-41.

52. Lobo RA. Evaluation of cardiovascular event rates with hormone therapy in healthy, early postmenopausal women: results from 2 large clinical trials. Arch Int Med 2004;164:482-4. 